\title{
ANALISIS PERBANDINGAN PENDAPATAN USAHATANI ANTARA POLA TANAM PADI-PADI DAN PADI-JAGUNG DI KECAMATAN BAMBEL KABUPATEN ACEH TENGGARA
}

\author{
(A Comparative Analysis Of The Income Of Farming Between Planting Patterns Of Rice-Rice \\ And Rice-Corn In Southeast Aceh Regency Bambel)
}

\author{
Sarah Muliana, Lukman Hakim, Mustafa Usman* \\ ${ }^{1}$ Program Studi Agribisnis, Fakultas Pertanian, Universitas Syiah Kuala
}

\begin{abstract}
Abstrak. Saat ini para petani di Kabupaten Aceh Tenggara banyak menanami tanaman padi pada lahan sawahnya dikarenakan masuknya varietas bibit unggul serta pengairan untuk mengairi sawah petani sudah sangat baik. Hal ini sangat berbanding terbalik pada beberapa tahun yang lalu dimana saluran irigasi tidak tersedia dengan baik sehingga petani banyak membudidaya tanaman jagung pada lahan sawahnya. Namun demikian, sebagian besar petani masih membudidaya tanaman jagung pada lahan sawahnya dikarenakan faktor lahan yang mendukung untuk ditanami jagung serta kebiasaan petani sendiri dalam mengusahakan lahannya untuk menanami tanaman jagung. Tujuan penelitian ini adalah untuk mengetahui perbedaan pendapatan usahatani antara pola tanam padi-padi dan padi-jagung di Kecamatan Bambel Kabupaten Aceh Tenggara. Metode penelitian yang digunakan adalah metode survey, wawancara, observasi dan kuesioner serta kuantitatif. Hasil penelitian menunjukkan rata-rata pendapatan usahatani per hektar yang menggunakan pola tanam padi-padi sebesar Rp 48.672.779 per Ha/MT dan Rp 48.810.638 jika digabungkan maka sebesar Rp 97.483.417,58 per tahun dan yang menggunakan pola tanam padi-jagung sebesar Rp 49.324.627 per Ha/MT dan Rp 19.438.487 per Ha/MT jika digabungkan maka sebesar Rp 68.763.113,07 per tahun. Dari hasil yang diperoleh dari perhitungan perbandingan menunjukkan bahwa $\overline{\mathrm{X}}_{1}>\overline{\mathrm{X}}_{2}$ dimana dari hasil perhitungan menggunakan statistik uji $\mathrm{t}$ didapat nilai $t_{\text {hitung }}>\mathrm{t}_{\text {tabel }}(11,358>2,013)$ dengan derajat kebebasan $(\mathrm{df})=46$ dan taraf nyata $(\alpha)=0,05$, dengan demikian terima Ha tolak Ho, yaitu Pendapatan usahatani pola tanam padi-padi berbeda dibandingkan dengan padi-jagung yakni pendapatan usahatani pola tanam padi-padi lebih besar dibandingkan dengan pola tanam padi-jagung.
\end{abstract}

Kata kunci: Pola Tanam, Usahatani, Pendapatan

Abstract. Currently, farmers in Southeast Aceh Regency cultivate many rice crops in their fields due to the inclusion of improved varieties of seeds and irrigation to irrigate rice fields of farmers have been very good. This is very reversed in the past few years where irrigation channels are not available so well that many farmers cultivate corn crops on their paddy fields. However, most farmers still cultivate corn crops in their paddy fields due to land supporting factors for cultivating maize as well as farmers' own habits in cultivating their land for cultivating corn crops. The purpose of this research is to know the difference of farm income between paddy-rice and paddy-rice pattern in Bambel District of Southeast Aceh Regency. The research method used is survey method, interview, observation and questionnaire and quantitative. The result of the research shows that the average of farm income per hectare using rice cropping pattern of Rp 48,672,779 per Ha / MT and Rp 48,810,638 if combined is Rp 97,483,417,58 per year and using rice cropping pattern corn amounting to Rp 49,324,627 per Ha / MT and Rp 19,438,487 per Ha / MT if combined then amounted to Rp 68,763,113,07 per year. From the results obtained from the comparative calculation shows that $\overline{\mathrm{X}} 1>\overline{\mathrm{X}} 2$ where from the calculation using $\mathrm{t}$ test statistics obtained tcount $>$ ttable $(11,358>2.013)$ with degrees of freedom $(\mathrm{df})=46$ and the real level $(\alpha)=0.05$, with thus received Ha Ho stall, ie Rice farming income pattern of rice-rice is different compared with the rice-maize income rice farming pattern-rice is greater than the pattern of rice-corn planting.

Keywords: Cropping Pattern, farm, Income

*Corresponding author: musthafa_usman@unsyiah.ac.id 


\section{PENDAHULUAN}

Kabupaten Aceh Tenggara merupakan salah satu wilayah yang ditetapkan oleh Kementerian Pertanian pada tahun 2016 sebagai wilayah sentra pembudidaya produksi jagung hibrida yang terbesar di Aceh. Menurut data BPS tahun 2015 Hasil produksi tertinggi ialah pada tanaman jagung sebesar 184.833,37 ton, diikuti oleh tanaman padi sebesar 137.584,82 ton. luas lahan tanaman jagung mengalami penurunan sebesar $0,01 \%$ pertahun dan produksi juga mengalami penurunan sebesar $0,01 \%$ pertahun. Adapun pada produktivitas jagung pertahun mengalami penurunan dengan laju $0,001 \%$ pertahun. Sedangkan pada luas lahan padi mengalami peningkatan sebesar $0,09 \%$ pertahun dan produksi $0,09 \%$ pertahun. Namun pada produktivitas padi mengalami penurunan dengan laju 0,007\% pertahun.

Saat ini para petani di Kabupaten Aceh Tenggara banyak menanami tanaman padi pada lahan sawahnya dikarenakan masuknya varietas bibit unggul serta pengairan untuk mengairi sawah petani sudah sangat baik. Hal ini sangat berbanding terbalik pada beberapa tahun yang lalu dimana saluran irigasi tidak tersedia dengan baik sehingga petani banyak membudidaya tanaman jagung pada lahan sawahnya. Namun demikian, sebagian besar petani masih membudidaya tanaman jagung pada lahan sawahnya dikarenakan faktor lahan yang mendukung untuk ditanami jagung serta kebiasaan petani sendiri dalam mengusahakan lahannya untuk menanami tanaman jagung.

Selain itu, biaya produksi juga menjadi kendala bagi petani jagung dimana biaya produksi yang dikeluarkan lebih besar dibandingkangkan dengan biaya produksi untuk tanaman padi. Adapun perbedaan harga jual yang tidak menentu sehingga petani lebih berminat untuk menanami tanaman padi pada lahan usahataninya karena petani cenderung melihat dari sisi keuntungan pada usahataninya.

Tujuan dilaksanakan penelitian ini adalah untuk mengetahui perbedaan pendapatan usahatani antara pola tanam padi-padi dan padi-jagung di Kecamatan Bambel Kabupaten Aceh Tenggara.

\section{Lokasi dan Waktu Penelitian}

\section{METODE PENELITIAN}

Penelitian ini dilakukan di dua desa yaitu Desa Kuta Lang Lang dan Desa Lawe Hijo di Kecamatan Bambel Kabupaten Aceh Tenggara. Penelitian ini berlangsung pada bulan Juni 2017 sampai bulan Frbruari 2018.

\section{Objek dan Ruang Lingkup Penelitian}

Objek penelitian adalah petani padi sawah. Ruang lingkup penelitian adalah pendapatan usahatani yang melakukan pola tanam padi-padi dan padi-jagung.

\section{Sumber dan Metode Pengumpulan Data}

Data yang diperoleh selama proses penelitian melalui proses wawancara, observasi dan kuisioner akan dianalisis secara kuantitatif. Metode kuantitatif digunakan untuk menghitung perbedaan pendapatan usahatani yang menggunakan pola tanam padi-padi dan padi-jagung. Data yang diperolah akan ditabulasi (data disajikan dalam bentuk tabel) agar lebih mudah dipahami. Instrumen penelitian yang digunakan untuk membantu proses penelitian adalah kuisioner gabungan terbuka dan tertutup.

\section{Model Analisis}

\section{Analisis Pendapatan Usahatani}

Analisis Perbandingan Pendapatan Usahatani Antara Pola Tanam Padi-Padi dan Padi-Jagung 
A. Biaya Total Produksi

$T C=F C+V C$

(Soekartawi, 2002)

Dimana :

$\mathrm{TC}=$ Total Cost $(\mathrm{Rp} / \mathrm{Musim}$ Tanam $)$

$\mathrm{FC}=$ Fixed Cost (Rp/Musim Tanam)

$\mathrm{VC}=$ Variable Cost $(\mathrm{Rp} / \mathrm{Musim}$ Tanam $)$

B. Penerimaan

$T R=P x Q$

(Soekartawi, 2002)

Dimana :

$\mathrm{TR}=$ Total Revenue $(\mathrm{Rp} / \mathrm{Musim}$ Tanam)

$\mathrm{P} \quad=$ Tingkat Harga $(\mathrm{Rp} / \mathrm{kg})$

$\mathrm{Q} \quad=$ JumlahProduksi $(\mathrm{kg})$

C. Pendapatan

$\pi=T R-T C$

(Soekartawi, 2002)

Dimana :

$\pi \quad=$ Keuntungan $(\mathrm{Rp})$

$\mathrm{TR}=$ Total Penerimaan $(\mathrm{Rp})$

$\mathrm{TC}=$ Total Biaya $(\mathrm{Rp})$

\section{Analisis Perbandingan Pendapatan Usahatani}

Untuk mengetahui perbandingan pendapatan usahatani yang menggunakan pola tanam padi-padi dan padi-jagung maka digunakan uji perbandingan Uji-t sampel bebas (Independent Sample t Test) yakni:

Dimana :

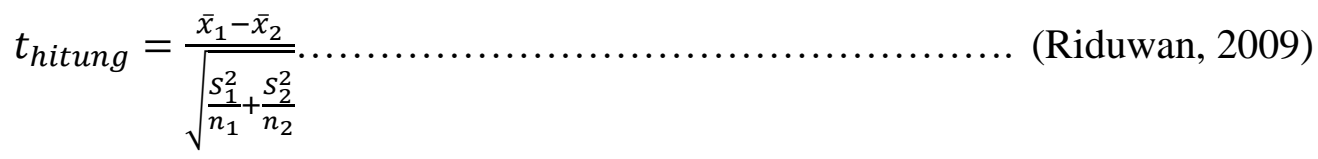

$\bar{x}_{1} \quad=$ Rata-rata pendapatan usahatani pola tanam padi-padi

$\bar{x}_{2} \quad=$ Rata-rata pendapatan usahatani pola tanam padi-jagung

$S_{1}^{2} \quad$ = Devisiasi standar pendapatan usahatani pola tanam padi-padi

$S_{2}^{2} \quad=$ Devisiasi standar pendapatan usahatani pola tanam padi-jagung

$n_{1} \quad=$ Jumlah petani pola tanam padi-padi

$n_{2} \quad$ Jumlah petani pola tanam padi-jagung

Secara keseluruhan, analisis pendapatan dan perbandingan pendapatan dianalisis dan diuji menggunakan komputer dengan aplikasi SPSS 2.1.

\section{HASIL PENELITIAN DAN PEMBAHASAN}

\section{Analisis Pendapatan Usahatani Pola Tanam Padi-Padi dan Padi-Jagung MT1 dan MT2}

\section{A. Total Biaya Produksi}

Analisis Perbandingan Pendapatan Usahatani Antara Pola Tanam Padi-Padi dan Padi-Jagung 
Tabel 1. Rata-rata Penggunaan Biaya Produksi Per Hektar Per Musim Tanam pada Usahatani yang Menggunakan Pola Tanam Padi-Padi dan Padi-Jagung di Kecamatan Bambel Daerah Penelitian Tahun 2017.

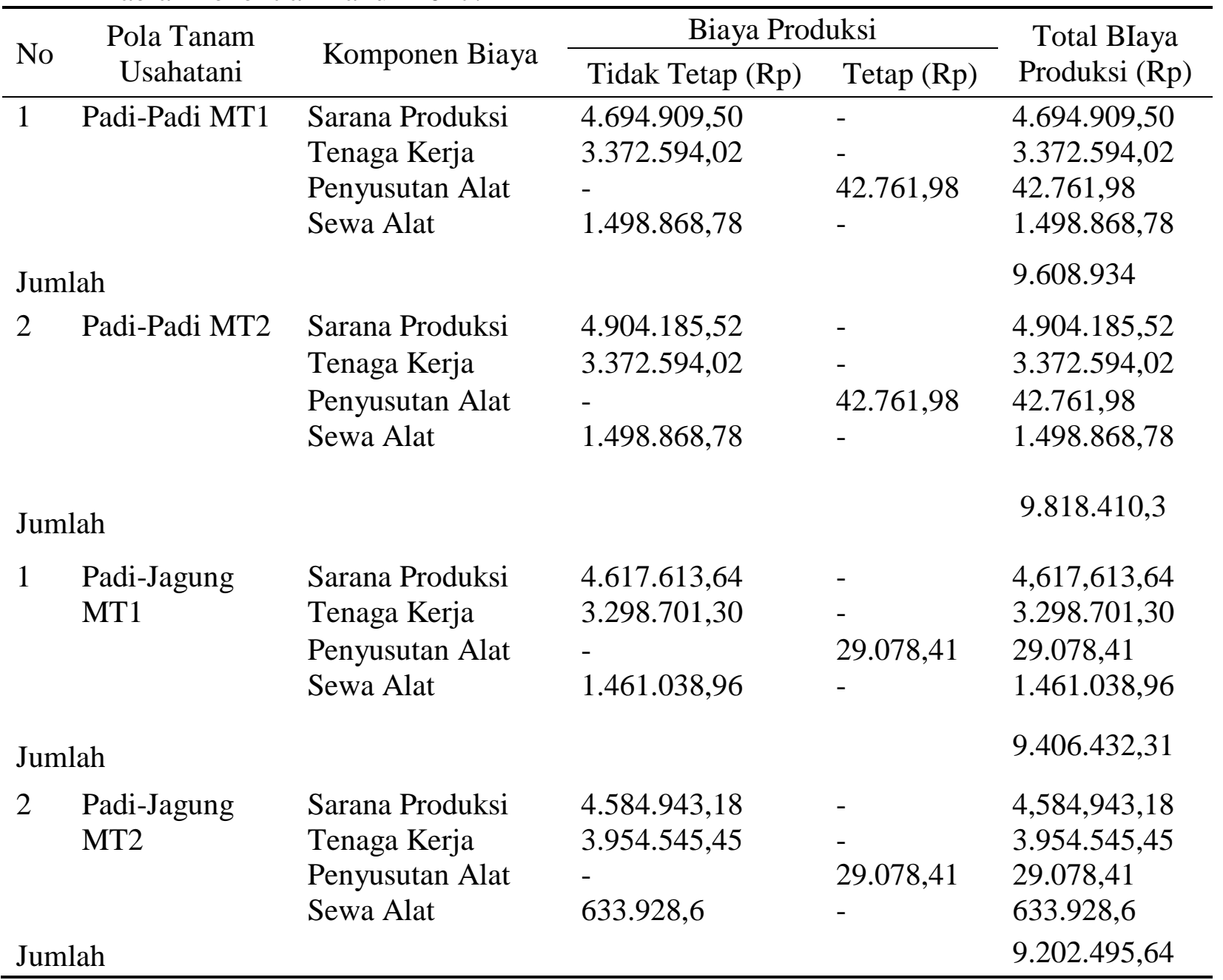

Sumber Data : Data Primer (diolah), 2018

Pada tabel diatas dapat dilihat bahwa total biaya produksi yang dikeluarkan petani pada usahatani pola tanam padi-padi dan padi-jagung dalam rata-rata per hektar pada pola tanam padi-padi musim tanam 1 yakni sebesar Rp 9.608.934 per Ha/MT dengan biaya sarana produksi sebesar Rp 4.694.909,50 per Ha/MT, biaya tenaga kerja per hektar sebanyak Rp 3.372.549,02 per Ha/MT, biaya penyusutan Rp $42.761,98$ per Ha/MT, dan biaya sewa alat sebesar Rp 1.498.868,78 per Ha/MT. adapun pada musim tanam 2 sebesar Rp 9.818.410,3 per Ha/MT dengan biaya sarana produksi sebesar Rp 4.904.185,52 per Ha/MT, biaya tenaga kerja per hektar sebanyak Rp 3.372.549,02 per Ha/MT dengan biaya penyusutan Rp 42.761,98 per Ha/MT dan biaya sewa alat sebesar Rp $1.498 .868,78$ per Ha/MT.

Adapun pada pola tanam padi-jagung musim tanam 1 sebesar Rp 9.406.432,31 per Ha/MT dengan biaya sarana produksi sebesar Rp 4.617.613,64 Ha/MT, biaya tenaga kerja per hektar sebanyak Rp 3.298.701,30 per Ha/MT dengan biaya penyusutan Rp 29.078,41 per Ha/MT, dan biaya sewa alat sebesar Rp 1.461.038,96 per Ha/MT. Adapun pada musim tanam 2 tanaman jagung sebesar Rp 9.202.495,64 per Ha/MT dengan biaya sarana produksi sebesar

Analisis Perbandingan Pendapatan Usahatani Antara Pola Tanam Padi-Padi dan Padi-Jagung 409

Di Kecamatan Bambel Kabupaten Aceh Tenggara (Sarah Muliana, Lukman Hakim, Mustafa Usman) Jurnal Ilmiah Mahasiswa Pertanian Unsyiah, Vol. 3, No. 4, November 2018: 406-415 
Rp 4.584.943,18 per Ha/MT, biaya tenaga kerja per hektar sebanyak Rp 3.954.545,45 per Ha/MT dengan biaya penyusutan Rp 29.078,41 per Ha/MT, dan biaya sewa alat sebesar Rp 633.928,6 per Ha/MT.

\section{B. Nilai Produksi}

Tabel 2. Rata-rata Produksi, Harga Jual dan Nilai Produksi yang Menggunakan Pola Tanam Padi-Padi Musim Tanam 1 dan 2 di Kecamatan Bambel Daerah Penelitian Tahun 2017

\begin{tabular}{lrrrr}
\hline & \multicolumn{4}{c}{ Pola Tanam Padi-Padi (Rp/Kg/MT) } \\
\cline { 2 - 5 } Hasil Produksi & \multicolumn{2}{c}{ Rata-rata per Petani } & \multicolumn{2}{c}{ Rata-rata per Hektar } \\
\cline { 2 - 5 } & Padi Musim & Padi Musim & Padi Musim & \multicolumn{1}{c}{ Padi Musim } \\
& Tanam 1 & Tanam 2 & Tanam 1 & Tanam 2 \\
\hline Luas Lahan (Ha) & 0,55 & 0,55 & 1 & 1 \\
Produksi (Kg) & $6.194,17$ & $6.235,88$ & $11.211,16$ & $11.286,65$ \\
Harga Jual Gabah (Rp) & 5.250 & 5.250 & 5.250 & 5.250 \\
Nilai Produksi (Rp) & 32.519 .375 & $32.738 .343,75$ & $58.858 .597,2$ & $59.254 .920,81$ \\
\hline
\end{tabular}

Sumber Data : Data Primer (diolah), 2018

Pada tabel diatas dapat dilihat bahwa rata-rata produksi petani yang mengusahakan usahataninya dengan menggunakan pola tanam padi-padi pada musim 1 per petani sebesar $6.194,17 \mathrm{~kg}$ per MT dengan harga jual gabah Rp 5.250 per Kg sehingga diperoleh nilai produksi sebesar Rp 32.519.375,00 per MT per Petani. Pada musim tanam 2 sebesar 6.235,88 per MT dengan harga jual gabah Rp 5.250 per Kg maka didapat nilai produksi sebesar Rp 32.738.343,75 per MT per Petani.

Adapun rata-rata produksi petani per hektar yang menggunakan pola tanam padi-padi pada musim tanam 1 didapat sebanyak $11.211,16 \mathrm{Kg}$ per Ha/MT dengan harga jual gabah Rp 5.250 per $\mathrm{Kg}$ sehingga diperoleh nilai produksi sebesar Rp 58.858.597,2 per Ha/MT. Pada musim tanam 2 sebesar 11.286,65 per Ha/MT dengan harga jual gabah Rp 5.250 per Kg maka didapat nilai produksi sebesar Rp 59.254.920,81 per Ha/MT.

Pada tabel diatas dapat dilihat bahwa rata-rata produksi petani yang mengusahakan usahataninya dengan menggunakan pola tanam padi-jagung pada musim 1 per petani sebesar $5.630,79 \mathrm{~kg}$ per MT dengan harga jual gabah Rp 5.250 per Kg sehingga diperoleh nilai produksi sebesar Rp 29.561.656,25 per MT per Petani. Pada musim tanam 2 yakni tanaman jagung diperoleh petani sebesar 4.011,08 per MT dengan harga jual jagung Rp 3.800 per Kg maka didapat nilai produksi sebesar Rp 15.242.116,67 per MT.

Selanjutnya rata-rata produksi petani per hektar yang menggunakan pola tanam padijagung pada musim tanam 1 didapat sebanyak 10969,07 Kg per Ha/MT dengan harga jual gabah $\mathrm{Rp} 5.250$ per $\mathrm{Kg}$ sehingga diperoleh nilai produksi sebesar Rp 57.587.642,05 per Ha/MT. Pada musim tanam 2 tanaman hasil produksi jagung yang diperoleh per hektar sebesar 7.813,80 per Ha/MT dengan harga jual jagung sebesar Rp 3.800 per Kg maka didapat nilai produksi sebesar Rp 29.692.435,06 per Ha/MT.

Terdapat perbedaan pada produksi yang dipengaruhi oleh perbedaan luas lahan yang mana rata-rata perhektar usahatani yang menggunakan pola tanam padi-padi sebesar 0,55 $\mathrm{Ha}$ /petani sedangkan yang menggunakan pola tanam padi-jagung sebesar $0,51 \mathrm{Ha} /$ petani sehingga mempengaruhi tinggi rendahnya produksi serta ketentuan harga yang berlaku juga

Analisis Perbandingan Pendapatan Usahatani Antara Pola Tanam Padi-Padi dan Padi-Jagung 
sangat mempengaruhi nilai produksi pada setiap musim tanam sehingga menyebabkan produksi pola tanam padi-padi lebih tinggi dibandingkan pola tanam padi-jagung.

Tabel 3. Rata-rata Produksi, Harga Jual dan Nilai Produksi yang Menggunakan Pola Tanam Padi-Jagung Musim Tanam 1 dan 2 di Kecamatan Bambel Daerah Penelitian Tahun 2017

\begin{tabular}{|c|c|c|c|c|}
\hline \multirow{3}{*}{ Hasil Produksi } & \multicolumn{4}{|c|}{ Pola Tanam Padi-Padi (Rp/Kg/MT) } \\
\hline & \multicolumn{2}{|c|}{ Rata-rata per Petani } & \multicolumn{2}{|c|}{ Rata-rata per Hektar } \\
\hline & $\begin{array}{l}\text { Padi Musim } \\
\text { Tanam } 1\end{array}$ & $\begin{array}{c}\text { Jagung } \\
\text { Musim } \\
\text { Tanam } 2\end{array}$ & $\begin{array}{l}\text { Padi Musim } \\
\text { Tanam } 1\end{array}$ & $\begin{array}{l}\text { Jagung Musim } \\
\text { Tanam } 2\end{array}$ \\
\hline Luas Lahan (Ha) & 0,51 & 0,51 & 1 & 1 \\
\hline Produksi $(\mathrm{Kg})$ & $5.630,79$ & $4.011,08$ & 10969,07 & $7.813,80$ \\
\hline $\begin{array}{l}\text { Harga Jual Gabah } \\
\text { (Rp) }\end{array}$ & 5.250 & - & 5.250 & - \\
\hline $\begin{array}{l}\text { Harga Jual Jagung } \\
\text { (Rp) }\end{array}$ & & 3.800 & - & 3.800 \\
\hline Nilai Produksi (Rp) & $29.561 .656,25$ & $\begin{array}{r}15.242 .116,6 \\
7 \\
\end{array}$ & $\begin{array}{r}57.587 .642,0 \\
5\end{array}$ & $29.692 .435,06$ \\
\hline
\end{tabular}

Sumber Data : Data Primer (diolah), 2018

\section{Pendapatan}

Dari tabel 4 dapat dilihat bahwa pendapatan petani yang menggunakan pola tanam padipadi pada musim tanam 1 adalah sebesar Rp 50.748.376,79 per Ha/MT yang diperoleh dari nilai produksi dikurangi dengan biaya produksi per musim tanam dimana nilai produksi sebesar Rp 58.858.597,2 per Ha/MT dan nilai biaya produksi sebesar Rp 8.110.220,50 per Ha/MT. Sedangkan pada musim tanam 2 adalah sebesar Rp 50.935.424,30 per Ha/MT yang diperoleh dari nilai produksi sebesar Rp 59.254.920,81 per Ha/MT yang dikurangi dengan biaya produksi sebesar Rp 8.319.496,52 per Ha/MT.

Tabel 4. Rata-rata Pendapatan Petani pada Usahatani yang Menggunakan Pola Tanam PadiPadi per Hektar Musim Tanam 1 dan Musim Tanam 2 di Kecamatan Bambel Daerah Penelitian Tahun 2017

\begin{tabular}{|c|c|c|c|c|}
\hline \multirow{2}{*}{ No } & \multirow{2}{*}{ Uraian } & \multirow{2}{*}{ Satuan } & \multicolumn{2}{|c|}{ Pola Tanam Rata-rata per Hektar } \\
\hline & & & Musim Tanam 1 (Padi) & Musim Tanam 2 (Padi) \\
\hline 1 & Produksi & $\mathrm{Kg}$ & $11.211,16$ & $11.286,65$ \\
\hline 2 & $\begin{array}{l}\text { Harga } \\
\text { Gabah }\end{array}$ & $\mathrm{Rp} / \mathrm{Kg}$ & 5.250 & 5.250 \\
\hline 3 & Nilai Produksi & $\mathrm{Rp} / \mathrm{Ha}$ & $58.858 .597,2$ & $59.254 .920,81$ \\
\hline 4 & Biaya Produksi & $\mathrm{Rp} / \mathrm{Ha}$ & $8.110 .220,50$ & $8.319 .496,52$ \\
\hline 5 & Pedapatan & $\mathrm{Rp} / \mathrm{Ha}$ & $50.748 .376,79$ & $50.935 .424,30$ \\
\hline
\end{tabular}

Sumber Data : Data Primer (diolah), 2018 
Dari tabel 5 dapat dilihat bahwa pendapatan petani yang menggunakan pola tanam padijagung pada musim tanam 1 dengan tanaman padi adalah sebesar Rp 51.103.287,66 per Ha/MT yang diperoleh dari nilai produksi sebesar Rp 57.587.642,05 dikurangi dengan biaya produksi per musim tanam sebesar Rp 7.783.055,68 per Ha/MT. Sedangkan pada musim tanam 2 dengan tanaman jagung adalah sebesar Rp 21.757.796,59 per Ha/MT yang diperoleh dari nilai produksi sebesar Rp 29.692.435,06 per Ha/MT yang dikurangi dengan biaya produksi sebesar Rp 8.568.567,05 per Ha/MT.

Tabel 5. Rata-rata Pendapatan Petani pada Usahatani yang Menggunakan Pola Tanam PadiJagung per Hektar Musim Tanam 1 dan Musim Tanam 2 di Kecamatan Bambel Daerah Penelitian Tahun 2017

\begin{tabular}{lllrr}
\hline & & Satuan & \multicolumn{2}{c}{ Pola Tanam Rata-rata per Hektar } \\
\cline { 3 - 5 } No & & $\begin{array}{c}\text { Musim Tanam 1 } \\
\text { (Padi) }\end{array}$ & $\begin{array}{c}\text { Musim Tanam 2 } \\
\text { (Jagung) }\end{array}$ \\
\hline 1 & Produksi & $\mathrm{Kg}$ & $10.969,07$ & $7.813,80$ \\
2 & Harga Jual Gabah & $\mathrm{Rp} / \mathrm{Kg}$ & 5.250 & - \\
3 & Harga Jual Jagung & $\mathrm{Rp} / \mathrm{Ha}$ & - & 3.800 \\
4 & Nilai Produksi & $\mathrm{Rp} / \mathrm{Ha}$ & $57.587 .642,05$ & $29.692 .435,06$ \\
5 & Biaya Produksi & $\mathrm{Rp} / \mathrm{Ha}$ & $7.783 .055,68$ & $8.568 .567,05$ \\
6 & Pedapatan & $\mathrm{Rp} / \mathrm{Ha}$ & $51.103 .287,66$ & $21.757 .796,59$ \\
\hline
\end{tabular}

Sumber Data : Data Primer (diolah), 2018

Sehingga terlihat perbedaan yang signifikan bahwa pendapatan petani yang menggunakan pola tanam padi-padi lebih besar dibandingkan dengan pendapatan petani yang menggunakan pola tanam padi-jagung.

\section{Uji Statistik Perbandingan Pendapatan}

Dari hasil perhitungan yang telah dianalisis diperoleh rata-rata pendapatan usahatani per hektar yang menggunakan pola tanam padi-padi sebesar Rp 48.672 .779 per Ha/MT dan Rp 48.810.638 jika digabungkan maka sebesar Rp 97.483.417,58 per tahun dan yang menggunakan pola tanam padi-jagung sebesar Rp 49.324.627 per Ha/MT dan Rp 19.438.487 per Ha/MT jika digabungkan maka sebesar Rp 68.763.113,07 per tahun.

Dari hasil yang diperoleh dari perhitungan perbandingan menunjukkan bahwa $\bar{X}_{1}>\bar{X}_{2}$ dimana dari hasil perhitungan menggunakan statistik uji $t$ didapat nilai $t_{\text {hitung }}>t_{\text {tabel }}(11,358>$ $2,013)$ dengan derajat kebebasan $(\mathrm{df})=46$ dan taraf nyata $(\alpha)=0,05$, dengan demikian terima Ha tolak Ho, yaitu pendapatan usahatani pola tanam padi-padi berbeda dibandingkan dengan padi-jagung yakni pendapatan usahatani pola tanam padi-padi lebih besar dibandingkan dengan pola tanam padi-jagung.

\section{Simpulan}

\section{SIMPULAN DAN SARAN}

Berdasarkan hasil penelitian dan pembahasan serta pengujian hipotesis menunjukkan bahwa pendapatan usahatani yang menggunakan pola tanam padi-padi terdapat perbedaan yang signifikan dengan pola tanam padi-jagung dimana pendapatan usahatani pola tanam padi-padi lebih besar dibandingkan pola tanam padi-jagung $\left(\bar{X}_{1}>\bar{X}_{2}\right)$ yakni sebesar $\mathrm{Rp} 48.672 .779$ per 
Ha/MT dan Rp 48.810.638 jika digabungkan maka sebesar Rp 97.483.417,58 per tahun dan yang menggunakan pola tanam padi-jagung sebesar $\mathrm{Rp} 49.324 .627$ per $\mathrm{Ha} / \mathrm{MT}$ dan $\mathrm{Rp}$ 19.438.487 per Ha/MT jika digabungkan maka sebesar Rp 68.763.113,07 per tahun.

\section{Saran}

Untuk meningkatkan pendapatan usahatani maka disarankan agar petani menggunakan pola tanam padi-padi. Selain itu petani juga disarankan agar dapat memilih lahan sawah yang selalu terpenuhi air irigasi untuk ditanami tanaman padi sedangkan dilahan sawah yang tidak terpenuhi air irigasi ditanami tanaman padi dan jagung serta lahan kering atau tegalan ditanami tanaman jagung agar dapat mempertahankan sebagai wilayah sentra produksi jagung dan meningkatkan produksi tanaman padi serta dapat meningkatkan pendapatan usahatani.

\section{DAFTAR PUSTAKA}

Agustyari, N. K., Antara, I. K., Anggreni, I. G. A. L., 2013. Perbandingan Pendapatan Usahatani Jagung Manis dan Padi di Subak Delod Sema Padanggalak Desa Kesiman Petilan Kecamatan Denpasar Timur. Universitas Udayana. Bali 2 (4).

Antara, M. 2010. Analisis Produksi dan Komparatif Antara Usahatani Jagung Hibrida Dengan Nonhibrida Di Kecamatan Palolo Kabupaten Sigi. Universitas Tadulako. Palu 17 (1).

Arfah, S. Y. C., Rauf, R. A., Sulaeman, H. 2013. Analisis Komparatif Pendapatan Usahatani Padi Sawah Sistem Tabela dan Sistem Tapin (di Desa Dolago Kecamatan Parigi Selatan Kabupaten Parigi Moutong). Universitas Tadulako. Kota Palu 1 (3).

Asmara, R. dan Nurholifah, R. 2010. Analisis Pendapatan Dan Faktor-Faktor Yang Mempengaruhi Pendapatan Petani Tebu Dalam Keanggotaan Suatu Koperasi. Unniversitas Brawijaya. Malang 10 (2).

[BPS] Badan Pusat Statistik. 2016. Produksi Jagung dan Padi di Kabupaten Aceh Tenggara 2016. www.acehtenggarakab.bps.go.id. Diakses pada 16 Maret 2017.

[BPS] Badan Pusat Statistik. 2016. Produksi Tanaman Pangan di Provinsi Aceh 2016. www.acehtenggarakab.bps.go.id. Diakses pada 27 Maret 2017.

Daniel, M. 2002. Metode Penelitian Sosial Ekonomi. Bumi Aksara. Jakarta.

Gifelem, C. N., Rine., Ruauw, E. 2016. Perbandingan Pendapatan Usahatani Jagung Manis dan Jagung Biasa di Desa Tontalete Kecamatan Kema Kabupaten Minahasa Utara. Universitas Sam Ratulangi. Manado 12 (2).

Hanum, C. 2008. Teknik Budidaya Tanaman :Jilid 1. Departemen Pendidikan Nasional. Buku Sekolah Elektronik. Jakarta.

Hasanah, I. 2007. Bercocok Tanam Padi. Azka Mulia Media. Jakarta.

Herawati, W. D. 2012, Budidaya Padi, Javalitera. Jogyakarta.

Kuheba, J. A., Andrew, J., Dumais, J. N. K., Pangemanan, P. A. 2016. Penelitian ini tentang Perbandingan Pendapatan Usahatani Campuran Berdasarkan Pengelompokan Jenis Tanaman. Universitas Sam Ratulangi. Manado 12 (2A).

Kuswono., Slamet., Suratiningsih, S.2012. Analisis Perbandingan Pendapatan Usahatani Ubi Kayu Jenis Daplang Dan Jenis Markonah Di Desa Metaraman Kecamatan Margorejo Kabupaten Pati. Sekolah Tinggi Ilmu Pertanian. Semarang 30 (2).

Lumintang, F. M. 2013. Penelitian Tentang Analisis Pendapatan Petani Padi Di Desa Teep Kecamatan Langowan Timur. Universitas Sam Ratulangi. Manado 1 (3) : 991-998.

Analisis Perbandingan Pendapatan Usahatani Antara Pola Tanam Padi-Padi dan Padi-Jagung 
Makarim, A. K. dan Ikhwani. 2012. System of Rice Intensification (SRI) dan Peluang Peningkatan ProduksiPadiNasional. Pusat Penelitian dan Pengembangan Tanaman Pangan. Bogor.

Makarim, A. K dan Suhartatik, E. 2009. Morfologi dan Fisiologi Tanaman Padi. Balai Besar Penelitian Tanaman Padi. Sukabumi. Subang.

Muchtadi, T. R. 2010. Ilmu Pengetahuan Bahan Pangan. Alfabeta. Bandung.

Novitan. 2002. Petunjuk Pemupukan yang Efektif. Agromedia Pustaka. Jakarta.

Poli, C. 1992. Pengantar Ilmu Ekonomi I Buku Panduan Mahasiswa. Gramedia Pustaka Utama. Jakarta.

Prihatman, K. 2000. Budidaya Padi. Pendayagunaan dan Pemasyarakatan Ilmu Pengetahuan Dan Teknologi. Jakarta.

Purwonodan, R. H. 2008. Bertanam Jagung Unggul. PS. Jakarta.

Puspito, J. 2011. Analisis Komparatif Usahatani Padi (Oryza sariva L.) Sawah Irigasi Bagian Hulu dan Sawah Irigasi Bagian Hilir Daerah Irigasi Bapang Kabupaten Sragen. Universitas Sebelas Maret. Surakarta.

Putra, D., Indra, C., Nyayu, N. A.2015. Analisis Produksi Dan Efisiensi Usahatani Padi Sawah Di Kecamatan Enggano Kabupaten Bengkulu Utara. Undergraduated thesis, Universitas Bengkulu. Bengkulu.

Qhoirunisa, A. S. dan Nurmalina, R. 2013. Pendapatan Usahatani Padi Hibrida dan Padi Inbrida di Kabupaten Bogor Propinsi Jawa Barat. Institut Pertanian Bogor. Bogor 22 (4).

Rahmadani, S., Salmiah, S., Kesuma, S. I. 2013. Analisis Perbandingan Tingkat Pendapatan Usahatani Pola Diversifikasi Dengan Monokultur pada Lahan Sempit. Universitas Sumatera Utara. Medan 2 (1)

Randhika, M., Antara, M., Rauf, R. A. 2015. Analisis Komparatif Pendapatan Usahatani Padi Sawah Peserta Program dan Tanpa Program Pemberdayaan Petani Melalui Teknologi dan Informasi Pertanian. Universitas Tadulako. Kota Palu 3 (2)

Rauw, L. E., Ngangi, C. R., Ruauw, E., Kumaat, R. M. 2014. Perbandingan Keuntungan Usahatani Padi Sawah dengan Teknik Tanam Pindah dan Teknik Tanam Benih Langsung di Dumoga Utara Kabupaten Bolaang Mongondow. Universitas Sam Ratulangi. Manado.

Riduwan. 2009. Metode dan Teknik Menyusun Tesis. Alfabeta. Bandung.

Rukmana, R. 2010. Jagung Budidaya, Pascapanen, Penganekaragaman Pangan. CV Aneka Ilmu. Semarang.

Sandiani, N. K. 2014. Analisis Komparatif Pendapatan Usahatani Padi Sawah Sistem Tanam Jajar Legowo 2:1 Dan 4:1 di Desa Puntari Makmur Kecamatan Witaponda. Universitas Tadulako. Palu 2 (2)

Sari, Y. N., Irnad, I., Redi, B. 2015. Analisis Perbandingan Pendapatan Usahatani Pola Tanam Padi-Padi Dengan Pola Tanam Padi-Jagung (Studi Kasus Di Desa Penandingan Kecamatan Air Nipis Kabupaten Bengkulu Selatan). Undergraduated thesis, Universitas Bengkulu. Bengkulu.

Setiani, N., Zakaria, W. A., Adawiyah, R. 2015. Analisis Keuntungan Usahatani Antar Pola Tanam Di Lahan Sawah Desa Tata Karya Kecamatan Abung Surakarta Kabupaten Lampung Utara. Fakultas Pertanian, Universitas Lampung. Bandar Lampung 3 (2)

Analisis Perbandingan Pendapatan Usahatani Antara Pola Tanam Padi-Padi dan Padi-Jagung 
Setjana, S. 1983. Perkembangan Penerapan Pola Tanam dan Pola Usahatani dalam Usaha Intensifikasi (Proyek BIMAS). Risalah Lokarya Teknologi dan Dampak Pola Tanam Usahatani. Pusat Penelitian dan Pengembangan Tanaman Pangan. Bogor.

Soeharjo dan Patong. 1994. Sendi-sendi Pokok Ilmu Usaha Tani. Departemen Ilmu Sosial Ekonomi FakultasPertanian IPB. Bogor.

Soekartawi. 2002. Analisis Usahatani. Universitas Indonesia. Jakarta.

Soekartawi. 1990. Teori Ekonomi Produksi, dengan Pokok Bahasan Analisis Fungsi CobbDouglas. Rajawali Pers. Jakarta.

Subekti, N. A., Syafruddin., Efendi, R., Sunarti, S. 2010. Morfologi Tanaman dan Fase Pertumbuhan Jagung. Balai Penelitian Tanaman Serealia, Maros.

Sudjana. 2002. Metode Statistika. Tarsito Bandung.

Sugiyono. 2012. Metode Penelitian Administrasi. Alfabeta. Bandung.

Sukirno dan Sadono. 2002. Teori Mikro Ekonomi. Cetakan Keempat Belas. Rajawali Press. Jakarta.

Suprapto. 1999. Percobaan Pada Tanaman Jagung Berdasarkan Frekuensi Air. Fakultas Pertanian IPB. Bogor.

Supriyono, R. 2011. Akuntasi Biaya, Perencanaan dan Pengendalian Biaya, serta Pengambilan Keputusan. BPFE. Yogyakarta.

Susilowati, J., Karyadi., Suratiningsih, S. 2011. Analisis Perbandingan Pendapatan Usahatani Padi Pengguna Pupuk Anorganik dan Yang Ditambah Pupuk Organik Di Desa Regaloh Kecamatan Tlogowungu Kabupaten Pati. Sekolah Tinggi Ilmu Pertanian. Semarang.

Zainnudin. 2009. Petunjuk Praktikum Terpadu Dasar-Dasar Agronomi. Lab Agronomi UMM. Malang. 